Volume 6, Issue 2 (2021), pp. 71-80

Journal of School Administration Research and Development

ISSN: 2470-8496 Print/ ISSN: 2470-850X Online

ojed.org/jsard

\title{
An Examination of Principal Professional Development and its Alignment to Professional Standards and Professional Development Constructs
}

\author{
Suzanne Rodriguez, Ed.D. \\ California State University, Fresno, USA \\ Jennifer Moradian Watson, Ed.D. \\ California State University, Fresno, USA \\ Mariya A. Yukhymenko-Lescroart, Ph.D. \\ California State University, Fresno, USA
}

\begin{abstract}
Principals need and require specific professional development that is rigorous, effective, and aligned to professional leadership standards and effective professional development constructs. This case study examined the professional development strategies, and practices, used by school districts and their alignment to the California Professional Standards for Educational Leaders (CPSEL) and effective professional development constructs. School district administrators and principals representing the Southern San Joaquin Valley, a predominantly rural area of California, participated in this research via interviews and focus groups. This research is critical as rural areas are often underrepresented in educational research. The findings indicate a lack of intentional alignment of principal professional development with professional standards and professional development constructs. The findings call for districts to take an intentional approach to principal development that is aligned with these frameworks to ensure principals are provided with effective and rigorous support for their educational leadership, growth, and development.
\end{abstract}

Keywords: principal professional development, school administration, leadership development

When the Covid-19 pandemic caused schools to shut down in 2020, it threw school districts and principals across the globe into crisis management. School leaders were tasked to unexpectedly innovate and manage the shift from face-toface to online instruction (Gigliotti, 2020). In addition to their multitude of duties, principals were also tasked with managing and responding to a myriad of extenuating factors like internet access, technology device distribution, teacher, student, parent training, and food insecurity; all while monitoring and adjusting to constantly changing local, state, and federal health guidance (Chennamsetti, 2020). The global pandemic crisis demanded skilled principal leadership and it exemplified the need to ensure the support and development of principal leadership capacity not only during principal preparation and times of crisis, but throughout their leadership career.

Principal professional development (PD) is critical due to the expectations and demands for school performance and the impact principals have on student achievement, which is only second to teachers (Branch et al., 2013; Bryk et al., 2010; Hitt \& Tucker, 2016; Manna, 2015; Rice, 2010). Consequently, principals require the same access to PD as teachers, which should be individualized to meet their specific needs (Bottoms \& Fry, 2009; Hoffman, 2004; Zellner et al., 2002), and aligned to professional leadership standards and PD constructs (George W. Bush Institute, 2016; Kearney, 2010; Kearney, 2015; Manna, 2015; Sun, 2011; Zepeda et al., 2014). However, California and other states are falling behind in the development and implementation of principal PD and require a more intentional system of support (Kearney, 2010; Riley \& Meredith, 2017). 
The purpose of this study was to conduct an examination of what California school districts are doing to provide principal PD that is aligned to the California Professional Standards for Education Leaders (CPSEL) and effective PD constructs. The research intended to answer the research question: what professional development strategies and practices used in school districts are aligned to the CPSEL and effective professional development constructs? Further analysis included alignment of district principal development to the CPSEL and to effective research-based PD constructs.

\section{LITERATURE REVIEW}

Principals of kindergarten through twelfth grade (K-12) schools are accountable for the academic achievement of their students and report to school boards, district leaders, staff, community, parents, and students. State mandates and increasing accountability for student achievement, graduation rates, and college and career preparation make 21st principal leadership complex and demanding (Fullan 2002; Hargreaves \& Goodson, 2006; Manna, 2015). As Scott and Webber (2008) asserted, "principals' roles encompass more diverse duties and expectations, ranging from instructional leader to financial manager to policy developer, decision maker, staff mediator and negotiator, and marketer" (p. 765). Principals are responsible for the overall organizational management and instructional leadership of schools and require a specialized set of skills to lead effectively. Yet, principals continue to lack systemic support and PD they need, especially when compared to teachers.

In most other organizations, employees are provided with a systematic method or continuum of PD for advancement and are expected to follow steps for their continued growth and development (Scott \& Webber, 2008). In education, leaders are often left to their own devices and provided with "ad hoc, hit-and-miss, on-the-job learning" (Scott \& Webber 2008 , p. 773). Principals need to be provided with systematic PD that is aligned to professional standards like the national Interstate School Leaders Licensure Consortium (ISLLC) Standards for School Leaders (2008) or, specific to California, the CPSEL, and aligned with effective PD constructs (George W. Bush Institute, 2016; Kearney, 2015; Manna, 2015; Zepeda et al., 2014). The alignment of both professional leadership standards and effective PD constructs to principal PD is key to ensure that adequate evaluation and measurement of principal development and capacity is assessed, identified, and effectively provided throughout a continuum of principal leadership. The alignment of principal PD with professional standards can also provide principal supervisors with a framework and context for principal supervision, not only in California, but anywhere principal supervisors and principals coexist.

\section{THEORETICAL FRAMEWORK}

This study is framed by leadership development theory which emphasizes that individuals learn at different rates and in different ways throughout their development and require specific skills that are more important and beneficial at different phases in their career (Day et al., 2014). Leadership development theory also asserts that the development of these leadership skills, and knowledge, occur over a career continuum (Mumford et al., 2000). This study is also supported by human capital theory, which insists there is an underlying belief in employee learning capacity and that investing in training, education, and development of employees results in profit for the organization, the individual, and their communities (Aliaga, 2001; Nafukho et al., 2004; Schultz, 1961). A related framework, Principal Talent Management (PTM), focuses on human capital management and the recruitment, development, and retention of school leaders (George W. Bush Institute, 2016). The key to cohesive leadership development of the framework is to ensure that each component is rooted in professional standards and closely communicated and coordinated within and between organizations that oversee each component (George W. Bush Institute, 2016).

\section{Principal Pipeline}

This research contributes to a global principal pipeline initiative that supports a continuum of principal development efforts and specific activities related to the preparation, hiring, development, evaluation, and support of school leaders (Kaufman et al., 2017; Gates et al., 2019). Supporting the principal pipeline to support school leaders is critical because when principals do not receive PD, they are 1.4 times more likely to leave their schools than principals who do (National Center for Education Statistics, 2013). Principal departures negatively impact student achievement, school culture, and district finances (Béteille et al., 2012; School Leaders Network, 2014). The fiscal impact of principal turnover is significant. Nearly $18 \%$ of principals in the United States exit the principalship within one year and it costs a school district an estimated \$75,000 each time a principal leaves a school (School Leaders Network, 2014). 


\section{Professional Standards for Educational Leaders}

Professional standards provide a framework for the preparation, induction, development, and evaluation of educational leaders. Many states have adopted and adapted their educational leadership standards from the ISLLC and aligned them to fit their educational systems and conditions (Kearney, 2015). For example, the state of California utilizes the CPSEL as their framework for principal leadership. The CPSEL include the following standards from the California Commission on Teacher Credentialing (2017):
1. Development and Implementation of a Shared Vision
2. Instructional Leadership
3. Management and Learning Environment
4. Family and Community Engagement
5. Ethics and Integrity
6. External Context and Policy (pp. 32-33).

Each of these standards also contain elements and indicators. The standards and elements are meant to provide a foundation for principal leadership in California and serve as a critical component for continuous principal development, professional learning, evaluation, and retention (Commission on Teacher Credentialing, 2017). However, many school districts fail to align professional standards to principal PD or utilize them as a framework to identify areas of professional competency or areas for continued and ongoing growth (Kearney, 2010; Manna, 2015; Sun, 2011).

In fact, principal PD, support, and evaluation in most states, including California, do not easily trace back to state adopted professional standards for educational leaders (Sun, 2011). To establish a cycle of continuous improvement in the development of principal leaders in California, it is critical that stakeholders apply the CPSEL to the design, development, implementation, and evaluation of principal PD (Kearney, 2010; Manna, 2015). Utilization of the CPSEL statewide would allow for standardized leadership that systematically exemplifies and supports what principals should be able to know and do as principal leaders in California (Kearney, 2010).

\section{Professional Development Definition and Constructs}

Varying definitions exist for PD. However, common definition characteristics of PD center on knowledge and skill building opportunities that increase professional capacity and improve performance related to organization and employee goals and needs (Elmore, 2002; Kearney, 2010; Norton, 2008). Based on their extensive literature review in best practices in PD, Fogarty and Pete (2004) identify five critical constructs of rigorous PD:

(1) Sustained: training is implemented over time.

(2) Job-embedded: training occurs and/or continues at the work site.

(3) Interactive: training invites, involves, and engages participants.

(4) Collegial: training builds and supports a community of learners.

(5) Integrated: training is eclectic (web-based, online, text, face to face) (p. 63).

The constructs support what the state of California identifies as key PD constructs for the California educational system (California Department of Education, 2012). For those reasons, the five constructs identified by Fogarty and Pete (2004) and two constructs supported by subsequent research, PD that is focused on student learning (California Department of Education, 2012) and PD that is provided on a continuum (Bishop et al., 2015), were utilized for the purposes of this research. The seven constructs were applied in this research to measure California district PD strategies and practices used and their alignment to the CPSEL and effective PD constructs.

\section{METHOD}

A qualitative case study design was utilized to obtain the data for this research. A policy analysis and examination of district administrator, principal practices, and perceptions was conducted. The case study for this research encompassed the geographical area of a portion of the California Central Valley, namely, the Southern San Joaquin Valley, and nine school districts within that area. The League of California Cities (2018) identified five counties and 37 cities within the case study region. The demographics of this area mirror California in that most of the ethnicities in this region are Hispanic/Latino, contain significant poverty rates, and speak a language other than English (California Department of Education, n.d.). 


\section{Site Selection}

Because many of the cities and counties in the case study region are known as agricultural and rural cities; the U.S. Department of Education Rural and Low-Income School Program (RLIS) allocation spreadsheet was used to identify the school districts, and the National Center for Education Statistics (NCES) locale code was used to identify each school district in these cities (U.S. Department of Education, n.d.). The NCES identifies school districts as either city, suburban, town, or rural, and each identifier contains three subtypes: large, midsize, and small (Geverdt, 2015). Using the RLIS allocation spreadsheet, the following criteria were used to identify school districts for this research:

1. Regular public-school district (non-charter).

2. District has five or more schools that include high, middle, and elementary schools.

3. District has one or more of the following NCES locale codes: city, suburban, town, rural, large, midsize, or small.

One additional criterion was added that was not directly related to the RLIS eligibility list:

4. District superintendent has been in current position for at least 6 months.

\section{Participants}

A purposive sample of eight superintendents and one designee, representing the nine districts in the case study, participated in individual semi-structured interviews. Principals from five of the nine districts participated in a semistructured focus group, totaling 17 principal participants. For anonymity, the districts and corresponding district administrators and principals were coded as District A - I. The participants in the case study region represented a sample of districts that were diverse and representative of a range of locales including large, midsize, small, suburban, town, and rural-fringe school districts, and reflected the following demographics:

\section{District Administrators}

- $56 \%$ male, $44 \%$ female

- Average 2.04 years in their position

\section{Principals}

- $58 \%$ female, $42 \%$ male

- Average 3 years in their position and 4.7 years as a principal

- Ten principals worked in elementary school, four in middle school, and three in high school

Study participants were asked a series of standardized questions that inquired about principal PD topics, how principal PD was provided to principals in their districts, and were provided with a list of the CPSEL, PD constructs, and their respective definitions, to ascertain the research question.

\section{Data Sources}

In addition to individual semi-structured interviews and semi-structured focus groups, a review of school district documents that include PD plans and agendas specific to principals, and Title I funds, were used as data collection sources. Steps to ensure credibility and transferability were taken throughout. These steps included thick description of the data, rereading the descriptive data, documenting insights, personal reflection about the data via reflexive journaling, and peer review of interview protocols and interview transcripts (Bailey, 2007; Nowell et al., 2017).

\section{Protocols}

For the interviews and focus groups, two interview protocols were created by the researcher that included open-ended questions to elicit data necessary to answer each research question. One interview protocol was created for the superintendent interviews, and one protocol was created for the principal focus groups. Specific questions were developed for both sets of participants. The questions were created by the researcher and adapted from the Principal Support Framework (University of Washington Center for Educational Leadership, 2016) and the American School Leader Panel 
(ASLP) survey (Johnston et al., 2016). Participant interview and focus group questions were created to align to each research question to ensure that adequate data were collected to answer each research question.

\section{Analysis}

A hybrid thematic analysis approach was taken for data analysis. Hybrid thematic analysis includes both an inductive and deductive approach to data analysis (Braun \& Clarke, 2006; Nowell et al., 2017; Yukhymenko et al., 2014). The deductive portion of the data analysis was the application of the data collected to the CPSEL and effective PD constructs and identification of where they converged. The hybrid thematic analysis for this research followed the six stages as identified by Fereday and Muir-Cochrane (2006) to code and summarize the coded themes:

1. Develop code manual

2. Test the reliability of code

3. Summarize data and identify initial themes

4. Apply template of codes and additional coding

5. Connect the codes and identify themes

6. Corroborate and legitimize coded themes (p.5)

To ensure proper coding and theming of data, the researcher followed the six stages as outlined and moved back and forth between the stages throughout the duration of the data collection to ensure a reflective and rigorous process (Nowell et al., 2017; Yukhymenko et al., 2014). Following these steps allowed the researcher to organize and thoroughly review the data.

For deductive analysis, all raw data were coded and themed and the predetermined codes and corresponding raw data were recorded. Utilizing the hybrid thematic analysis approach allowed examination of the variance in participant perceptions and any possible unexpected phenomenon (Nowell et al., 2017). A preliminary codebook was created that included the CPSEL and the PD constructs. Any additional codes and themes that were counter to the preliminary codes were also added as needed to the data to accurately capture the data collected. The data collection and results were reported in narrative form that included a table matrix of findings and their relation to the CPSEL and effective PD constructs.

\section{RESULTS}

The results of this study are divided into two sections 1) district administrator participant results and 2) principal focus group participant results. Each section demonstrates results specific to principal PD alignment with the CPSEL and principal PD alignment with effective PD constructs.

\section{DISTRICT ADMINISTRATOR INTERVIEW RESULTS}

\section{Principal PD and CPSEL Alignment}

When asked how their district uses the CPSEL to identify principal PD needs, eight out of nine district administrators provided no direct response to their alignment of principal PD with the CPSEL. Instead, their responses primarily centered on a theme that included the lack of purposeful utilization of the CPSEL to provide principal PD or identify principal PD needs. One district administrator reported, "We don't necessarily use that to guide PD" (District Administrator G, personal communication, February 12, 2019) and another reported, "We are still growing in that area" (District Administrator D, personal communication, February 8, 2019). Although the CPSEL were not used by the majority of school districts to intentionally identify principal PD needs, most of the PD content and topics aligned to the CPSEL.

The primary PD practice utilized by school district participants that was aligned to the CPSEL was the principal evaluation tool and process. This was a common theme among districts. However, not all district principal evaluations were reported by school district participants to be aligned to the CPSEL. District administrator participants also did not report that the evaluation tool was utilized to determine principal PD, except for district E.

Utilizing a pre-determined codebook that included the six CPSEL, the principal PD topics district administrators reported were aligned to the CPSEL, as illustrated in Table 1. The principal PD topics mostly aligned to the CPSEL; however, the CPSEL was not purposefully utilized by district participants to develop and determine principal PD. The 
principal PD topics provided by district administrators also mostly aligned with the instructional leadership standard with the management and learning environment standard following closely behind. Few topics aligned with the remaining standards and no topics were found to align with the family and community engagement standard.

\section{Principal PD and Effective PD Constructs Alignment}

The district administrators reported that principal PD was primarily provided face-to-face, internally, and externally, and on and off campus. How principal PD was provided varied across districts. Common themes among districts included principal PD that was provided both onsite and off-campus, but few districts reported principal PD that was sustained, job-embedded, and provided throughout a continuum. District administrator E reported that principal PD was provided "On the job, collaborative and throughout the entire year" (District Administrator E, personal communication, February 8, 2019). District administrator H reported that principal PD was provided "Primarily off-campus- short term" (District Administrator H, personal communication, February 14, 2019).

Utilizing a pre-determined codebook that included the effective PD constructs identified for this study, how principal PD was provided, as reported by district administrators, aligned to the PD constructs, as illustrated in Table 2. Although Table 2 data indicate that principal PD provided by each district aligned with all seven effective PD constructs, how principal PD was provided to principals varied from district to district. Not one district was able to report that their principal PD aligned to each PD construct. Therefore, the alignment of principal PD and effective PD constructs are only based on what was reported by each district administrator and do not represent alignment across districts.

\section{PRINCIPAL FOCUS GROUP RESULTS}

\section{Principal PD and CPSEL Alignment}

The principal groups were asked what their experience has been with the CPSEL in relation to their principal PD. They were also asked how, and how often, the CPSEL are used by district administrators, including their direct supervisor, to support their growth and development. In response to those questions, all five principal groups reported the CPSEL was used by their district administrators to support their growth and development via the principal evaluation process. All principal groups reported that the principal evaluation process was also utilized to establish goals with their district administrator that are reviewed with them more than once a year.

Two principal groups reported that the CPSEL are embedded in other PD strategies and practices provided to principals in context, versus verbatim. One principal explained, "And I don't think it's handed to us like here's the standard. But in all the work that we do it definitely is integrated" (District Principal A, personal communication, March 4, 2019). Similar to district administrator responses, principal group responses centered on a theme that included the lack of purposeful utilization of the CPSEL to provide principal PD or identify principal PD needs.

In examination of the topics of PD provided to principals and their alignment to the CPSEL, as illustrated in Table 3, the principal PD topics aligned most with the following standards 1) Instructional Leadership, 2) Management and Learning Environment, and 3) External Context and Policy. Three of the six CPSEL, Development and Implementation of a Shared Vision, Family and Community Engagement, and Ethics and Integrity, aligned the least.

\section{Principal PD and Effective PD Constructs Alignment}

Utilizing a pre-determined codebook that included the seven effective PD constructs for this study, how principal PD was provided, as reported by principal groups, were aligned to the PD constructs, as illustrated in Table 4. How principal PD was provided to principals varied in each district. Common themes among principal groups included principal PD that was provided in various formats but primarily onsite and off-campus. Not one principal group was able to report that their PD aligned to every PD construct and the PD provided to all principal groups collectively aligned to all effective PD constructs except two: Interactive and Continuum of PD Throughout Career.

\section{DISCUSSION, IMPLICATIONS, CONCLUSIONS}

The findings identified robust principal PD that covered a myriad of PD topics supported by district administration. These district principal PD efforts demonstrated an underlying belief in principal learning capacity and investment in training and development of their leaders, which is a true representation of human capital theory. However, the findings also identified areas where districts and principal supervisors could benefit from increased evaluation and development of their 
principal PD practices, including ensuring principal PD is inclusive of individual principal needs and aligned to the CPSEL, and effective PD constructs.

\section{CPSEL Alignment}

Both the district administrator and principal group interview data revealed that the primary district PD practice aligned to the CPSEL was the principal evaluation tool and process. The principal data revealed that the principal evaluation tool was used to establish goals with their district administrators. This practice is supported by research that asserts that the CPSEL should be used to provide school districts with a framework from which to evaluate and develop school principals (Kearney, 2010). Furthermore, policy makers have suggested that the CPSEL was developed to provide a structure for continuous principal development, professional learning, evaluation, and retention (Commission on Teacher Credentialing, 2017). However, for district administrators, not all districts reported alignment of the CPSEL to any of their district PD strategies or practices. The misalignment of PD to the CPSEL in some districts supports the research assertion that numerous school districts fail to align the CPSEL to principal PD (Kearney, 2010; Manna, 2015; Sun, 2011). Reflective of this research, districts also fail to utilize the CPSEL as a framework to identify areas of professional competency and provide ongoing principal PD and support (Kearney, 2010; Manna, 2015; Sun, 2011). Although the most recent ideation of the CPSEL is considered a high impact strategy in improving principal pipelines (Kaufman et al., 2017), many school districts and states fail to utilize them to support principal PD. The misalignment suggests a need for more targeted district use of professional leadership standards as a framework to identify principal PD needs and provide a continuum of principal PD and support throughout their leadership careers.

Examination of the alignment of the CPSEL to the PD provided to principals suggests one standard overwhelmingly represented by both district administrators and principal groups was the instructional leadership standard. The management and learning environment standard was a distant second. Minimal alignment was found in the following CPSEL: 1) development and implementation of a shared vision; 2) family and community engagement; 3) ethics and integrity; and 4) eternal context and policy. The data indicate the need for districts to be more intentional in their use of the CPSEL during the development and implementation of principal PD and support. Currently, much of the research on PD in education is primarily focused on teacher PD versus principal PD (Levine, 2015). It is critical that California, and all state stakeholders, consciously plan and apply leadership standards to the design, development, implementation, and evaluation of principal PD (Kearney, 2010; Manna, 2015). This practice will ensure that principals are developed in all areas of leadership that address all professional standards, not just instructional leadership.

\section{Effective PD Constructs Alignment}

Both the district administrator and principal group interview data revealed district practices aligned to at least one effective PD construct. However, the data indicate that the practices of each district were not aligned to all seven constructs. For example, some districts took intentional steps to ensure that the PD provided to principals was sustained throughout the year and supported with individual, ongoing principal coaching at the school site and other districts did not. Some districts require that principals attend PD side-by-side with their teachers, academic coaches, or co-leaders and some districts do not. Some districts provide a variety of PD delivery methods that include face-to-face and webinars and some districts provide only one form of interactive PD. The data reflect a need for intentional alignment and practice of effective PD constructs by districts when developing and providing principal PD and support.

The examination of pre-determined effective PD constructs with the PD provided to principals, demonstrated alignment with at least one PD construct. The principal responses aligned with all but two constructs: interactive and continuum of PD throughout a career. Specific to the lack of alignment of PD to a continuum of PD throughout a principal's career, this data conflicted with leadership development theory which asserts that individuals learn at different rates and in different ways and require specific skill development as they move through that career continuum (Day et al., 2014). As national and international research has demonstrated, even after being on the job for three or more years principals state they require ongoing support and development (Adamowski et al., 2007; Hourani \& Stringer, 2015). The data reflected a need for districts to provide a purposeful and systematic process that ensures principal PD throughout a principal's career. The implementation of these practices will ensure that PD is effectively used to support and sustain principal learning, development, and longevity.

Research argues that leadership qualities develop over time and through professional development (Day et al., 2008). The significance of this study underscores the urgency for school districts to take an intentional approach to principal PD with the same attention and effort they take with teacher PD. Districts need to engage in purposeful PD planning with 
their principals. Districts must also ensure that their principal PD is aligned to individual principal needs, professional standards, and effective PD constructs not just school site and broad stroke district needs and initiatives. Moreover, this study provides a research-based approach to principal PD and urges states and school districts to elicit change in policies and practices that positively impact the development of school leaders, contributes to student achievement, and ensures educational equity of students in all schools.

\section{REFERENCES}

Adamowski, S., Therriault, S.B., \& Cavanna, A.P. (2007). The autonomy gap: Barriers to effective school leadership. American Institutes for Research and Thomas B. Fordham Institute. https://files.eric.ed.gov/fulltext /ED496189.pdf

Aliaga, A. O. (2001). Human capital, HRD and the knowledge organization. In A.O. Aliaga (Ed.), Proceedings from AHRD Conference: Academy of Human Resource Development. (pp.427-434). https://files.eric.ed.gov/fulltext/ED453406.pdf

Bailey, C. (2007). Introduction to qualitative field research. A guide to qualitative field research. Sage.

Béteille, T., Kalogrides, D., \& Loeb, S. (2012). Stepping stones: Principal career paths and school outcomes. https://www.urban.org/sites/default/files/publication/32851/1001531-

Stepping-Stones-Principal-Career-Paths-and-School-Outcomes.PDF

Bishop, J., Darling-Hammond, L., \& Jaquith, A. (2015). Maximizing the use of new state professional learning investments to support student, educator, and school system growth: State guidance for key district stakeholders. Learning Policy Institute. https://files.eric.ed.gov/fulltext/ED606456.pdf

Bottoms, G., \& Fry, B. (2009). The district leadership challenge: empowering principals to improve teaching and learning. $\quad \mathrm{https} / /$ www.wallacefoundation.org/knowledge-center/Documents/District-Leadership-ChallengeEmpowering-Principals.pdf

Branch, G., Hanushek, E., \& Rivkin, S. (2013). School leaders matter: Measuring the impact of effective principals. Education Next 13, 1-8.

Braun, V., \& Clarke, V. (2006). Using thematic analysis in psychology. Qualitative Research in Psychology, 3(2), 77-101. https://www.researchgate.net/publication/235356393 Using thematic analysis in psychology

Bryk, A. S., Sebring, P. B., Allensworth, E., Luppescu, S., \& Easton, J. Q. (2010).Organizing schools for improvement: Lessons from Chicago. The University of Chicago Press.

California Department of Education. (2012). Greatness by design: A report by state superintendent of public instruction Tom Torlakson's task force on educator excellence. https://www.cde.ca.gov/eo/in/documents/greatnessfinal.pdf

California Department of Education (n.d.), Fiscal, demographic, and performance data on California's K-12 schools. https://www.ed-data.org/index

Chennamsetti, P. (2020). Assisting school leaders in overcoming challenges. Journal of School Administration Research and Development. Volume 5, Issue S2, pp. 93-99.

Commission on Teacher Credentialing. (2017). Administrative services standards booklet.

https://www.ctc.ca.gov/docs/default-source/educator-prep/standards/asc-admin-handbook.pdf?sfvrsn=48

Day, D. V., Fleenor, J. W., Atwater, L. E., Sturm, R. E., \& McKee, R. A. (2014). Advances in leader and leadership development: A review of 25 years of research and theory. Leadership Quarterly, 25(1), 63-82. https://doi.org/10.1016/j.leaqua.2013.11.004

Day, D., Harrison, H., \& Halpin, S. (2008). An integrative approach to leader development, identity and expertise. Routledge.

Elmore, R. (2002). Bridging the gap between standards and achievement. The Albert Shanker Institute.

Fereday, J., \& Muir-Cochrane, E. (2006). Demonstrating rigor using thematic analysis: A hybrid approach of inductive and deductive coding and theme development. International Journal of Qualitative Methods, 5(1), 80-92. https://doi.org/10.1177/160940690600500107

Fogarty, R.J. \& Pete, B.M., 2004. The adult learner: Some things we know. Corwin Press.

Fullan, M. (2002). Leadership and sustainability. Principal Leadership, 3(4), 1-8. https://michaelfullan.ca/wpcontent/uploads/2016/06/13396047460.pdf

Gates, S. M., Baird, M. D., Master, B.K., \& Chavez-Herrerias, E, 2019. Principal pipelines: A feasible, affordable, and effective way for districts to improve schools. RAND Corporation, 2019. https://www.rand.org/pubs/research_reports/RR2666.html 
George W. Bush Institute. (2016). Principal talent management according to the evidence: A review of the literature. George W. Bush Institute. https://files.eric.ed.gov/fulltext/ED587185.pdf

Geverdt, D. (2015). Education demographic and geographic estimates program (EDGE): Locale boundaries user's manual (NCES 2016-012). https://nces.ed.gov/programs/EDGE/docs/NCES_LOCALE_USERSMANUAL 2016012.pdf

Gigliotti, R., (2020). Sudden shifts to fully online: Perceptions of campus preparedness and implications for leading through disruption. The Journal of Literacy and Technology, 21 (2).

Hargreaves, A. \& Goodson, I. (2006). Educational change over time? The sustainability or non-sustainability of three decades of secondary school change and continuity, Educational Administration Quarterly, 42(1), 3-41.

Hitt, D.H. \& Tucker, P.D. (2016). Systematic review of key leader practice found to influence student achievement: A unified framework. Review of Educational Research, 86(2), 531-560. https://journals.sagepub.com/doi/10.3102/0034654315614911

Hoffman, J. (2004). Building resilient leaders. Leadership, 34, 35-38.

Hourani, R., \& Stringer, P. (2015). Professional development: Perceptions of benefits for principals. International Journal of Leadership in Education, 18(3), 305-339. https://doi.org/10.1080/13603124.2014.904003

Interstate School Leaders Licensure Consortium. (2008). Educational leadership policy standards 2008: As adopted by the National Policy Board for Educational Administration in 2007. https://www.danforth.uw.edu/uwdanforth/media/danforth/isllc-2008.pdf

Johnston, W. R., Kaufman, J. H., \& Thompson, L. E. (2016). Support for instructional leadership. https://www.rand.org/content/dam/rand/pubs/research_reports/RR1500/RR1580-1/RAND_RR1580-1.pdf

Kaufman, J. H., Gates, S. M., Harvey, M., Wang, Y., \& Barrett, M. (2017). What it takes to operate and maintain principal pipelines: Costs and other resources. https://www.wallacefoundation.org/knowledgecenter/Documents/What-It-Takes-to-Operate-and-Maintain-Principal-Pipelines.pdf

Kearney, K. (2010). Effective principals for California schools: Building a coherent leadership development system. WestEd.

Kearney, K. (Ed.). (2015). Moving leadership standards into everyday work: Descriptions of practice (2nd ed.). WestEd.

League of California Cities (2018). South San Joaquin Valley division. League of California Cities. https://www.cacities.org/Member-Engagement/Regional-Divisions/South-San-Joaquin

Levine, A. (2015). School principals should be trained like MBAs. https://www.realcleareducation.com/articles/2015/02/04/school_principals_should_be_trained_like_mbas_1153.html

Manna, P. (2015). Developing excellent school principals to advance teaching and $\bar{l}$ earning: $\bar{C}$ Considerations for state policy.

Wallace

Foundation. https://www.house.ga.gov/Documents/CommitteeDocuments/2017/Leadership_Academy/1/Developing-ExcellentSchool-Principals.pdf

Mumford, M., Marks, M. A., Connelly, M. S., Zaccaro, S. J., \& Reiter-Palmon, R. (2000). Development of leadership skills: Experience and timing. The Leadership Quarterly, 11(1), 87-114.

Nafukho, F. M., Hairston, N. R., \& Brooks, K. (2004). Human capital theory: Implications for human resource development. Human Resource Development International, $7(4), \quad 545-\quad 551$. https://doi.org/10.1080/1367886042000299843

National Center for Education Statistics, Institute of Education Sciences. (2013). Schools and Staffing Survey (SASS). U.S. Department of Education.

Norton, S. (2008). Human resources administration for educational leaders. Sage.

Nowell, L. S., Norris, J. M., White, D. E., \& Moules, N. J. (2017). Thematic analysis: Striving to meet the trustworthiness criteria. International Journal of Qualitative Methods, 16(1), 1-13. https://doi.org/10.1177/1609406917733847

Rice, J. K. (2010). Principal effectiveness and leadership in an era of accountability: What research says. https://files.eric.ed.gov/fulltext/ED509682.pdf

Riley, D. L., \& Meredith, J. (2017). State efforts to strengthen school leadership: insights from CCSSO action groups. https://files.eric.ed.gov/fulltext/ED580215.pdf

School Leaders Network (2014). CHURN: The High Cost of Principal Turnover. http://iowaascd.org/files/7014/5978/0122/principal_turnover_cost.pdf

Schultz, T. W. (1961). Education and economic growth: Social forces influencing American education. University of Chicago Press. 
Scott, S., \& Webber, C. F. (2008). Evidence based leadership development: the 4L framework. Journal of Educational Administration, 46(6), 762-776. https://doi.org/10.1108/09578230810908343

Sun, C. (2011). School leadership: Improving state systems for leader development (NASBE discussion guide). https://www.wallacefoundation.org/knowledgecenter/Documents/NASBEDiscussion-Guide-School-LeadershipImproving-State-Systems-for-Leader-Development.pdf

University of Washington Center for Educational Leadership (2016). Principal support framework. http://info.k12leadership.org/principal-support-framework

U.S. Department of Education. (n.d.) REAP allocation spreadsheet [Data file]. https://www2.ed.gov/programs/reapsrsa/fy18reapallocationspreadsheet.xlsx

Yukhymenko, M., Brown, S. W., Lawless, K., Brodowinska, K., \& Mullin, G. (2014). Thematic analysis of teacher instructional practices and student responses in middle school classrooms with problem-based learning environment. Global Education Review, 1(3), 93-109.

Zellner, L., Jinkins, D., Gideon, B., Doughty, S., \& McNamara, P. (2002). Saving the principal: The evolution of initiatives that made a difference in the recruitment and retention of school leadership. https://files.eric.ed.gov/fulltext/ED467670.pdf

Zepeda, S. J., Parylo, O., \& Bengtson, E. (2014). Analyzing principal professional development practices through the lens of adult learning theory. Professional Development in Education, 40(2), $295-315$. https://doi.org/10.1080/19415257.2013.821667

SUZANNE RODRIGUEZ, EdD, is a Lecturer in the Department of Social Work Education at California State University, Fresno and a Forensic Expert with Robson Forensic, Inc. Dr. Rodriguez's major interests lie in the areas of principal professional development, leadership development, human resource management, school administration, and social work. Email: szrodri@csufresno.edu

JENNIFER MORADIAN WATSON, EdD, is an Assistant Professor in the Department of Educational Leadership at California State University, Fresno. Dr. Moradian Watson's major research interests are teacher retention, principal preparation, and the equitable implementation of the teaching and learning process.

MARIYA A. YUKHYMENKO-LESCROART, PhD, is an Associate Professor of Research and Statistics in the Department of Curriculum and Instruction at California State University, Fresno. She holds M.A. (2009) and Ph.D. degrees (2012) in educational psychology with focus on research methodology from the University of Connecticut; and M.A. degree (2019) in sport psychology from California State University, Fresno. Dr. Yukhymenko's research focuses on the substantive-methodological synergy. For methodological interests, she is particularly interested in scale development and validation and in application of multilevel and structural equation modeling to the empirical data. Her substantive interests lie in the intersection of positive, educational, and sport psychology, with focus on positive development of college students and adults, and in providing methodological support to the research of other scholars. 